\title{
Health Challenges for Non-Communicable Diseases Among Faculty, Staff and Administrators in Selected Higher Educational Institutions
}

\author{
Emilie M. Lopez \\ Woosong University, Daejeon City, Korea \\ emilie2819@yahoo.com.ph
}

\begin{abstract}
This descriptive-comparative study aimed to assess health challenges for NonCommunicable Diseases (NCD) among faculty, staff and administrators in Higher Educational Institutions (HEI). Health profiling of 741 faculty, staff and administrators as respondents of the study in their respective universities was measured from Summer, 2015 to 1st Semester, Academic Year 2015-2016 utilizing a survey questionnaire. World Health Organization (WHO) STEPWISE Approach-Risk Assessment Tool revealed that respondents were all at risk for developing cardiovascular diseases, diabetes, cancer, and chronic respiratory diseases. The research hypotheses showed a significant difference of risk factors between faculty and staff, and between administrators and staff. However, no significant difference existed between the group of faculty and administrators.
\end{abstract}

Keywords: Health, Challenges, Non-communicable diseases, Higher educational institutions, Faculty, Staff, Administrators

\section{Introduction}

Every country in the world is currently facing the burden and battle of combating against the epidemic of non-communicable diseases (NCD), which is locally and globally considered as a major threat to public health [1][2][3][4]. As to what extent these are attended is now put into challenge with the most productive members of the society among Higher Educational Institutions (HEI) were assessed of their health challenges and health promotion action areas [5][2] Health profiling yielded those health challenges for NCD among the three groups of respondents and established significant difference between these group of faculty, staff and administrators. Consequently, findings of the study would serve as a springboard for future studies that would require specific actions for setting the basic foundation in illness prevention and areas for health promotion.

\section{Study goal}

This study aimed to determine and assess health challenges for NCD among faculty members, staff and administrators in selected HEI. It further investigated the significant difference among the respondents' health challenges. Specifically, it sought to answer the

Article history:

Received (May 18, 2018), Review Result (July 19, 2018), Accepted (October 17, 2018) 
questions that determined the profile of the respondents in terms of the following health risk factors classified into non-modifiable such as age and gender, and modifiable ones. Those modifiable risk factors included Body Mass Index (BMI), Blood Pressure (BP), personal history of hypertension, diabetes, increase of cholesterol, smoking history, alcohol drinking history, diet, physical activity and medications taken for cholesterol, hypertension and blood sugar. The other questions assessed the health challenges that can be identified based on the respondent's assessed health profile. Finally, significant difference was established among the faculty, staff and administrators in terms of their health challenges as they were grouped according to their health profiles.

\section{Method}

This paper was a descriptive comparative study which examined the health challenges for Non-Communicable Diseases (NCD) among faculty, staff and administrators in six HEI. Respondents of the study consisted of members of the faculty, administrative staff and administrators who belonged to the U-belt Consortium in the City of Manila. In the Philippines, this U-belt Consortium is an association of Manila's leading HEI which consists of 13 member-institutions of which six (6) universities formally expressed their interest and participation in the study.

All of the 1,200 respondents who were presently employed during the conduct of the study automatically became the respondents where survey questionnaires have been distributed. There were 820 forms retrieved from the six schools, however, a total of 741 questionnaires were considered because other survey questionnaires had incomplete answers, hence, were disregarded.

The major instrument used in the gathering of data covered the respondents' health profiles which sought to determine the health challenges. For this purpose, the WHO STEPWISE Approach module was utilized in determining the health risks of the respondents in terms of the eleven risk factors as previously indicated. Findings from the study tools were tabulated, analyzed, interpreted and presented using the Statistical Package for the Social Sciences (SPSS).

\section{Results and discussion}

\subsection{General information of the respondents' health profile assessment}

The respondents' health profiling revealed that majority of those who belong to this group was female, young adult members of the academic community who were considered overweight, obese or pre-hypertensive. Majority preferred intake of processed foods and intake of fast foods several times in a week. In their daily food regimen, consumption of fruits and vegetables of less than five servings a day was noted. They did not engage in moderate to intense physical activity as well. Those respondents with known history of medical conditions

like hypertension, diabetes and increase of blood cholesterol were taking prescribed medications from their respective physicians.

\subsection{Respondents' health challenges based on the health profile variables}

Based on the health profile assessment of the respondents, all were identified at risk for NCD particularly of cardiovascular disorders, diabetes, cancer and chronic obstructive 
pulmonary disease (COPD) with an average of 3-6 risk factors that the respondents would have failed.

Recent statistics and reports both locally and globally have shown that the leading causes of mortality and morbidity are no longer infectious diseases but more of the chronic, debilitating NCD which include heart diseases, diabetes, cancer and COPD. These NCD are known as "lifestyle diseases" because the social environment in which the individual lives plays a significant role in determining the person's level of health. Establishing environments conducive to healthy living definitely creates that big challenge of maintaining good nutrition, physical activity and healthy way of living. [2][3][4][5].

\subsection{Respondent's number of risk factors classified according to with or without modifiable risk factors}

Table 1. Frequency and percentage distribution of the respondents' number of risk factors classified according to with or without modifiable risk factors

\begin{tabular}{|c|c|c|c|c|c|}
\hline \multirow{2}{*}{$\begin{array}{l}\text { Number of } \\
\text { Risk Factors }\end{array}$} & \multicolumn{2}{|c|}{$\begin{array}{c}\text { *With Modifiable } \\
\text { Risk Factors }\end{array}$} & \multicolumn{2}{|c|}{$\begin{array}{c}* * \text { Without Modifiable Risk } \\
\text { Factors }\end{array}$} & \multirow[t]{2}{*}{ Total } \\
\hline & Frequency & Percentage & Frequency & Percentage & \\
\hline 1 & 3 & 0.40 & 0 & 0 & 3 \\
\hline 2 & 29 & 3.91 & 0 & 0 & 29 \\
\hline 3 & 137 & 18.49 & 0 & 0 & 137 \\
\hline 4 & 177 & 23.89 & 0 & 0 & 177 \\
\hline 5 & 171 & 23.08 & 0 & 0 & 171 \\
\hline 6 & 129 & 17.41 & 0 & 0 & 129 \\
\hline 7 & 68 & 9.18 & 0 & 0 & 68 \\
\hline 8 & 21 & 2.83 & 0 & 0 & 21 \\
\hline 9 & 4 & 0.54 & 0 & 0 & 4 \\
\hline 10 & 2 & 0.27 & 0 & 0 & 2 \\
\hline Total & 741 & 100 & 0 & 0 & 741 \\
\hline
\end{tabular}

Out of the total 741 respondents, all have at least one (1) modifiable risk factor identified in their health profile. [Table 1] further showed that 177 respondents have four (4) risk factors wherein the respondents have at least one modifiable risk factor out of those total four (4) risk factors identified. Majority of the respondents have 3-6 of these modifiable risk factors as assessed in their health profile. These findings reveal that all of the respondents with at least one (1) modifiable risk factor can still be helped by a health/wellness program to reduce their risks of further developing any of those NCD of the heart, vascular system, respiratory system and all sorts of cancer.

Based on a study conducted by S. Peterson, V. Peto, P. Scarborough, and M. Rayner, (2006), it was emphasized that evidences accumulated during the last few years had identified a number of factors contributing to the risk of coronary heart disease include increasing age, a family history of heart disease and male (gender) which will definitely predispose a person for having any of the NCD in the long run [6][7]. Other risk factors for coronary heart disease can be changed depending on a persons' lifestyle, otherwise, these risk factors are precursors for higher than average rate of mortality and morbidity rates [8]. 


\subsection{Significant difference among respondents' health challenges}

It could be noted from [Table 2] that the respondents had significant difference established in terms of their assessed modifiable risk factors (MRF) and health challenges, hence, rejection of the null hypothesis. The respondents may vary from each other in terms of the total risks acquired out of the total eleven (11) risk factors that have been identified in their health profile and the Modifiable Risk Factors (MRF) which can further be classified as common and intermediate. Common MRF of chronic or persistent and long-lasting NCD pertains to unhealthy diet, physical inactivity and tobacco and alcohol use, age and heredity, whereas the intermediate MRF include raised blood sugar, raised blood pressure, abnormal blood lipids and overweight/obesity [8]. Other disease precursors include demographic variables, certain individual behaviors, family and individual histories, and certain physiologic changes occurring in normal and healthy functioning of the body [8].

Table 2. Welch's test of difference among respondents' health challenges

\begin{tabular}{|c|c|c|c|c|c|c|}
\hline & Welch & df1 & df2 & p value & Interpretation & Decision on Ho \\
\hline $\begin{array}{c}\text { Modifiable Risk } \\
\text { Factors }\end{array}$ & 7.123 & 2 & 152.881 & .001 & Significant & Rejected \\
\hline
\end{tabular}

As gleaned from the result of the finding of the study, the respondents of the study when grouped accordingly have significant difference in the identified risk factors classified as modifiable risk factors. Specifically, the group of respondent differs in the number of modifiable risk factors that they have. All of them have at least one modifiable risk factor assessed.

If a person therefore is already at risk because of the presence of at least one of these risk factors, individual's decision to participate and commit oneself is critical and strategies to prevent the so-called lifestyle related diseases can offer a logical alternative for a person. In this regard, the environment where the individual works will be crucial to consider. Each of the health-promoting lifestyles can be affected by the environment in itself. However, aggressive lifestyle modification is needed for people with existing non-modifiable risk factors coupled with any of the modifiable risk factors as well.

Table 3. Dunnet $\mathrm{C}$ multiple test of differences in the three groups of respondents in terms of the health challenges

\begin{tabular}{|c|c|c|c|c|}
\hline \multirow{2}{*}{ (I) type } & $(\mathrm{J})$ type & Mean Difference (I-J) & Interpretation & Decision on Ho \\
\hline \multirow{2}{*}{ Faculty } & Staff & $.367^{*}$ & Significant & Rejected \\
\cline { 2 - 5 } & Administrator & -0.163 & Not Significant & Accepted \\
\hline \multirow{2}{*}{ Staff } & Administrator & $-.530^{*}$ & Significant & Rejected \\
\hline
\end{tabular}

Furthermore, [Table 3] depicts the result on the test of differences in the three (3) groups of respondents in terms of their health challenges. As illustrated, significant difference existed between the faculty and staff, that is, with mean difference of .367 results, and between staff and administrators, with mean difference of -0.530 results, hence, rejection of the null hypothesis were considered. On the other hand, no significant difference in terms of the modifiable risks factors and health challenges that existed between the group of faculty and 
administrators with mean difference of -0.163 results, hence, acceptance of the null hypothesis.

These findings of the study as depicted from Table 3 imply that the group of faculty respondents has greater risk factors compared to the staff and administrators whereas the staff has lesser risks compared to the faculty and administrators. This can probably be attributed to the fact that the group of staff belonged to a younger group of the population and years of environmental exposure counts in the possibility of having more modifiable risks factors accumulated over a period of time.

Additionally, the respondents' nature of job can be essentially considered wherein workrelated stress can become a disease-promoting agent. In general, stress has been identified as a risk factor for hypertension, diabetes, upper extremity musculoskeletal back problems, and cardiovascular disease [9]. It can also be attributed to external factors that include the physical environment where job, relationships with others, home, and all the situations, challenges, difficulties, and expectations confronted with on a daily basis are part of. How the body's ability to respond to and deal with these external stressors cover the other internal factors of stress [9]. Specifically in this study, the nature of the respondents' work as vulnerable risk groups can possibly pose a threat to the health of individual worker, and in turn, to the organization in particular.

Based on personal observations and professional experiences as one of the faculty members and clinical instructor in the undergraduate and postgraduate courses, and former administrator in a College of Nursing, teachers' work days do not end when leaving the classroom or hospital premises. There are extra things that must be done such as making of learning plans, preparing for classroom activities, regular or periodic examinations, grading tests and reviewing tools for Related Learning Experience in the clinical area of assignments.

\section{Conclusion}

Based on the aforementioned findings of the study, the following conclusions were derived:

(1) The faculty, staff, and administrators in the selected HEI were all identified at risk for developing NCD, with an average of 4-5 risk factors that the respondents would have failed.

(2) There was significant difference in the risk factors and the non-modifiable risk factors result of the findings of the study between faculty and staff and between administrators and staff. However, no significant difference existed between the group of faculty and administrators

\section{Acknowledgement}

The author would like to express her deepest appreciation to the University Presidents, directors, administrators and staff of selected academic institutions for their approval and warm welcome together with the faculty members, administrators and staff of the selected six (6) HEI in answering the questionnaire. Likewise, to the Philippine Nurses Association (PNA) for the scholarship grant and to friends, colleagues, staff and administrators in Arellano University-Main Campus, and the Graduate School of Nursing professors in the completion of this study. More importantly, to the Almighty God and to her family who is the greatest inspiration and strongest pillar for the unconditional love and encouragement. 
Health Challenges for Non-Communicable Diseases Among Faculty, Staff and Administrators in Selected Higher Educational Institutions

\section{References}

[1] Department of Health Republic of the Philippines, Health beat, Official Publication of the Department of Health, vol.64, (2011)

[2] WHO The Ottawa Charter for Health Promotion, Geneva: WHO, www.who.int/health-pro-mo-tion/conferences/previous/ottawa.../index1.ht, (2010)

[3] Department of Health, Morbidity: 10 Leading Causes, Number and Rate 2010, http://www.doh.gov.ph/kp/statistics/morbidity.html, (2010)

[4] W. H. O., "Global Action Plan for the Prevention \& Control of Non-Communicable Diseases 2013-2020," Geneva: W.H.O., (2013)

[5] WHO STEPWISE Approach, "Risk Factor's Assessment and Screening Procedures - Module 2, A Training Manual for Health Workers on Healthy Lifestyle: An Approach for the Prevention and Control of NonCommunicable Diseases," www.wpro.who.int/philippines/publications/module2.pdf, (2010)

[6] R. Langford, C.P. Bonell, H.E. Jones, T. Pouliou, S.M. Murphy, E. Waters, K.A. Komro, L. Gibbs, D. Magnus, and R. Campbell, "The WHO Health Promoting School framework for improving the health and well-being of students and their academic achievement," Cochrane Database of Systematic, no.CD008958, (2014) DOI:10.1002/14651858.CD008958

[7] S. Peterson, V. Peto, P. Scarborough, and M. Rayne, "Coronary Heart Disease Statistics - 2005 edition," British Heart Foundation Health Promotion Research Group, Department of Public Health, University of Oxford, (2006)

[8] T.M. Usman, "Modifying health risk factors DOH center for health development," Autonomous Region in Muslim Mindanao, vol.68, (2012)

[9] M.C. Stoppler, Stress, Medicine Net.com, http://www.medicinenet.com/ stress/article.htm, (2014)

\section{Author}

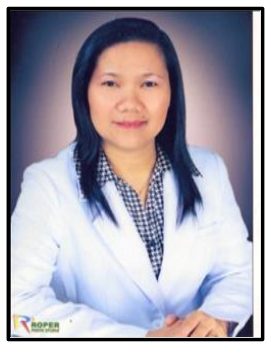

\section{Emilie Marin- Lopez}

Dr. Lopez earned her Master of Arts degree in Nursing and doctorate degree in educational administration from the Pamantasan ng Lungsod ng Maynila in the Philippines. She served as Dean, College of Nursing in Manila Tytana Colleges, 4th year Level and Research Coordinator at Arellano University, Main Campus, Chapter Service Representative in both the Nursing and Safety Services at the Philippine National Red CrossManila Chapter and Department Manager for Personnel Management at Chong Hua Hospital. She was a board exam reviewer among undergraduate and professor of graduate students in the areas of medical-surgical nursing, leadership and management, research and emergency/disaster nursing and instructional management in nursing. She is currently an Assistant Professor at the Department of Nursing, College of Health and Welfare, Woosong University, Republic of Korea. 